\title{
LOS ORGANISMOS INSTITUCIONALES DE LOS AYUNTAMIENTOS
}

Por Vicente BOIX REIG

Profesor de Derecho Administrativo

\author{
S. U M A R I Q
}

1.-La organización y el ordenamiento administrativo.

1.1. La organización social.

1.2. El ordinamentalismo.

1.3. Organización y ordenamiento.

2.-La aplicación de la anterior corriente de pensamiento al Derecho municipal español.

2.1. De la atribución de competencias a organizaciones municipales.

2.2. Los valores localistas.

2.3. La atracción centralista sobre la Administración institucional.

3.-Ordenamiento y organización institucional municipal.

4.-Análisis ordinamentalista sobre los Entes institucionales de los Ayuntamientos.

4.1. La creación del Ente institucional municipal.

4.2. El ordenamiento del Ente institucional municipal.

4.3. Análisis tipológico de los organismos institucionales de los Ayuntamientos.

4.3.1. De la Mancomunidad.

4.3.2. Del Consorcio.

4.3.3. De la Agrupación.

4.3.4. De la Fundación pública de servicio.

4.3.5. De la Sociedad municipal.

4.3.6. De la Empresa mixta. 


\section{1.-LA ORGANIZACION Y EL ORDENAMIENTO ADMINISTRATIVO}

\section{1.- La organización social}

Las teorías sobre la organización administrativa se han visto enriquecidas en los últimos tiempos con importantes aportaciones provinentes del campo de las Ciencias sociales. Las que han puesto de relieve, el fenómeno creciente de la autoafirmación de los colectivos sociales.

El ordinamentalismo jurídico-administrativo constituye la aportación doctrinal más notable dentro de esta línea de pensamiento: sé apoya en el formalismo keynesiano, y desde él se acerca al fenómeno social, buscando un difícil maridaje a fin de recomponer con realismo la comprensión jurídica de la estructura organizativa del Estado:

Dice SANTI ROMANO(1) que "la llamada crisis del Estado moderno implica por de pronto la tendencia de una serie enorme de grupos sociales, a construirse cada uno de ellos un reducto jurídico independienten; concluyendo, "toda fuerza que efectivamente sea social, se transforma por ello mismo en Derecho".

Pudiéndose concluir en la conveniencia de que el Derecho reconozca a tales fuerzas sociales, siempre que éstas estén revestidas de la cualidad de ser identificables por el propio ordenamiento, y en la medida en que se encajen dentro de los marcos autorizados por el poder soberano del Estado.

Una construcción doctrinal de tal calidad parece atractiva y abre los estudios de Ciencia política a nuevas fronteras, ampliando, no sólo los horizontes del Derecho constitucional y del Derecho administrativo, sino también los mismos criterios inspiradores de la distribución de competencias y de imputación de responsabilidades dentro de la.Administración pública. Es por ello por lo que, como dice MARTIN RETORTILLO, $S_{\text {(2), ila }}$ tesis ordinamentalista es frecuentemente asumida por distintos autores como punto de partida para llevar a cabo posteriores investigaciones".

\section{2.-El ordinamentalismo}

Quizás más mediterránea y sugestiva la de HAURIOU, y quizás más rigurosa la construcción del precitado profesor italiano, tienen ambas un mismo molde originario en la Escuela de Viena: el orden jurídico, asentado en el "yo social", se refleja en las normas jurídicas. Ese "yo social" es toda fuerza que efectivamente sea social, es decir que esté organizada, o lo que es lo mismo, que esté institucionalizada. La institución deviene así en la manifestación originaria y esencial del Derecho. $Y$ avanza esta doctrina afirmando que una institución adquiere el carácter de "persona», esto es de sujeto de derechos, cuando bien por su propio ordenamiento, bien por otro ordenamiento causante o causado por aquél, se califique como Ente 
con voluntad propia. Concluyendo por afirmarse que una organización o institución debe calificarse de "persona", cuando su misma estabilidad social transcienda y cree orden jurídico: estamos ante una singular concepción del derecho estatutario o conformador de personas.

El peligro de esta doctrina puede presentarse cuando se intente trasladar los centros de imputación social, del indivíduo a la institución, pues ello puede deslizar las conclusiones por sendas totalitarias. Quizás por eso Hauriou acomete una ardorosa revisión del esquema rousseauniano sobre la significación del grupo social, con sutiles distingos entre fuerza y poder, más atractivos que convincentes.

Parece que la tesis ordinamentalista es válida para plantear a nivel organicista la pluralidad y la indeterminación de las personas jurídicopúblicas en el Estado. E incluso parece útil para definir el criterio ordenador del reparto de competencias adminstrativas. Pero quizás esta teoría sea insatisfactoria para explicar y fúndămentar la dialéctica indivíduoEstado, libertad-Poder.

\section{3.-Organización y ordenamiento.}

El ordenamiento jurídico abstracto, es decir la organización social estable, se refleja formalmente en normas jurídico-positivas. Cuya función primordial será la de reconocer o regular a esas organizaciones naturales, calificándoles de organizaciones jurídicas.

Cuando una norma jurídica no refleja fielmente a la organización social, habrá que cuestionar su legitimidad. Organización, crdenamiento abstracto y norma positiva, puede ser el esquema de este Derecho de las organizaciones o de las personas jurdico-públicas, que figurativamente se manifestará como la clásica pescadilla que se muerde la cola.

Fundamentar en la misma "organización social» al entramado orgánico del Estado, precisa de algunas puntualizaciones:

a) Parece difícil que el Poder pueda detectar y dar soporte jurídico con agilidad, a las nacientes y dinámicas organizaciones, así como a los conjuntos humanos más o menos espontáneos que brotan en la sociedad. Lo que aconseja establecer en el Derecho positivo, unos entramados jurídicos muy primarios, con unos cauces formales más o menos generosos, que posibiliten la autonomía de las organizaciones que se vayan manifestando en la vida social. Decía DE LOS RIOS(3): «El Estado no es el único organo en la producción del Derecho, sino el órgano más importante». La afirmación tiene hoy su mejor actualidad.

b) Parece igualmente difícil prescindir de la figura de la upersonalidad», pues se precisa de alguna técnica para la imputación de responsabilidad a cualesquiera Entes. Pero será conveniente, ya que no prescindir de 
esta figura sobre la que se sigue sosteniendo el andamiaje jurídico del Poder, si modificar las reglas de su usg, a fin de darle más elasticidad, introduciendo un más rico pluralismo en el cuadro de Organismos con competencia para impartir esta vestimenta jurídica.

c) De algún modo los dos postulados que anteceden, están llamando a una revisión o reencuentro, en definitiva a una reafirmación entre las diversas "organizaciones sociales" y sus respectivos "yos jurídicos". A fin de que se adscriba a las auténticas «organizaciones espontáneas de la sociedad" y sólo a ellas, los definitorios protagonismos políticoadministrativos en la vida pública. Huyendo de los eufemismos y de las piruetas juridicas en el vacío, a las que tan acostumbrado ha venido siendo nuestro legislador administrativista(4).

d) $Y$ sintetizando, se debería subrayar la necesidad de que exista un reconocimiento a nivel de Ley formal, de la capacidad de las organizaciones para imprimir dinamismo a su "ordenamiento singular", y de que al mismo tiempo este ordenamiento singular capacite a su respectiva organización a autodictarse las normas positivas que deban regir la convivencia entre los propios miembros del mismo grupo social, y de éstos con otros ciudadanos o con otras organizaciones.

\section{2.-APLICACION DEL ORDINAMENTALISMO AL DERECHO MUNICIPAL ESPAÑOL.}

\section{1.-De la atribución de competencias a organizaciones municipales.}

Es un hecho, y la doctrina(5) y la jurisprudencia (6) lo han detectado con profusión, que como resultado de un largo proceso de empobrecimiento y languidecimiento de la vida local, el Poder ha descuidado a los Entes locales a la hora de distribuir competencias o de asignar cometidos de interés general. Se podría citar como ejemplo significativo al fenómeno del urbanismo, respecto al cual SERRANO y GARCIA DE ENTERRIA entre otros(7), han puesto de relieve que la presión de la concentración humana en las ciudades y que la influencia de la formación social industrial sobre las pautas urbanas, son tan evidentes que muchos de los males del raquitismo y de la hipertrofia de la vida local, derivan de la falta de un auténtico Poder municipal-atribución de competencias y dotación de medios para cumplir los fines-capacitado para contestar con eficacia a las demandas de la nueva sociedad.

El paquete de competencias públicas, no se ha adjudicado precisamente a la Administración municipal. ¿Fue acertada, lo es hoy día una decisión de tal calidad, que al desvincular a los centros organizativos municipales de los problemas socio-económicos modernos, los condenó a un oscuro ostracismo en el que continuan?. 
¿Qué contestación pueden dar a las debilitadas Administraciones municipales, las corrientes doctrinales ordinamentalistas, que buscan el engarce directo de la responsabilidad jurídica con las organizaciones sociales generadoras de Derecho?.

¿Sería interesante superar los dogmatismos de la estrecha teoría de la personalidad jurídico-pública, para abrir cauces a la asignación de responsabilidades a una mayor variedad de organizaciones?.

¿Podrá vigorizar el pensamiento ordinamentalista a los Entes institucionales de los Ayuntamientos, que siguen ofreciendo en la actualidad un penoso y raquítico balance de realizaciones?.

¿Cómo debe configurar nuestro Derecho a estos Entes?. Nuestras Leyes se muestran con frecuencia preocupadas en contraponer al Poder central, amplias, abstractas y vaporosas competencias municipales vacías de contenido. Frente a esta corriente habrá que ir pensando que en el tablero estatal del reparto de las competencias públicas es necesario reservar un espacio no sólo a los Entes locales en general y a los municipales en particular, sino también dentro de estos últimos a sus Organismos institucionales. Es más, parece necesario concretar con rigor jurídico cual es exactamente el espacio que metodológimante corresponde a los Entes institucionales de la Administración municipal.

El tradicional recelo legislativo en la eficacia operativa de los Ayuntamientos, y de las otras instancias locales y regionales, ha situado en la orbita centralista a buena parte del paquete de competencias públicas. Si no hubiera recelos ni prejuicios, la’s funciones municipales podrían ser más ricas. Habrá que someter a profunda revisión los criterios utilizados por el Estado para el reparto de competencias entre la Administración central y la municipal y naturalmente las otras instituciones locales y regionales, y bien podrá utilizarse la tesis ordinamentalista para tal depuración. Ya que parece incuestionable que el "yo social", célula primaria de la tesis ordinamentalista, es fácilmente detectable en los variados círculos municipales en los que se administran intereses públicos.

El "yo social" detectable en los círculos municipales constituye una organización social de mayor o menor calidad, que demanda una más amplia aceptación formal por el Derecho positivo del Estado; un más adecuado cauce jurídico para su expresión y su desarrollo.

\section{2.- Los valores localistas}

El problema estará en definir cuáles son los valores localistas que deben alentarse en cada coyuntura histórica. Por esta vía creemos:

a) Que los valores localistas existentes en un lugar y en un momento determinado, tendrán que ser detectados y tendrán que venir dados en su 
valor contingente y en su tensión dinámica, por la Ciencia y por la Sociología políticas. Esos valores concretos reflejarán la específica fuerza del conjunto social de que se trata.

b) Que un buen número de organizaciones municipales puedan ser reconocidas por el ordenamiento jurídico positivo. Tanto las territoriales como las institucionales.

La existencia jurídica de estas organizaciones municipales será la natural contestación del Derecho a las tendencias de la propia vida local. Valorar la bondad de un tal reconocimiento por el Derecho, es seguramente una necesaria tarea crítica.

c) Que el conjunto de organizaciones socio-económicas, sin las cuales no puede entenderse ni la vida moderna en general ni la vida municipal en concreto, es tan variado y cambiante que debe entenderse en permanente revisión. Revisión de las organizaciones, revisión de la esfera de poder a la que se adscribe una organización determinada, y revisión de los grados de poder de las diferentes organizaciones. Los valores locales. habrá que captarlos en cada coyuntura, y son algo discutible y por supuesto contingente. En cada circunstancia histórica debe haber una definición, una contestación del Derecho positivo a estos interrogantes, y ese mismo Derecho positivo deberá ser concreto en sus definiciones.

La dificultad y aun la imposibilidad de que un Derecho positivo pueda ser exhaustivo en su regulación, aconseja que ésta se realice con pautas indicativas, dentro de las cuales sea posible graduar la intensidad de las competencias con que conviene juridizar la capacidad operativa de cada organización.

La clave de bóveda para la armónica coexistencia del ordenamiento jurídico-positivo del Estado, con los ordenamientos jurídicos que puedan surgir de las organizaciones espontáneas de la sociedad, no parece que pueda ser otra, que la homologación por el único poder soberano del Estado, de esos ordenamientos jurídicos menores. La forma de realizarse esta homologación, será en definitiva una opción política del Poder público. Opción política qué tomará como variantes a las fuerzas sociales espontáneas y a las fuerzas jurídico-positivas; coordenadas en la dinámica de cada sociedad.

\section{3.-La atracción centralista sobre la Administración institucional.}

En la esfera local, y dentro de ella en la municipal, coexisten al igual que en la esfera central, Entes territoriales y Entes institucionales. Aquéllos, primarios o de primer grado, y éstos de segundo grado, esto es, nacidos de los respectivos Entes territoriales para prestar o gestionar servicios públicos por motivos varios que van desde los políticos hasta los de eficacia. 
Naturalmente la atracción centralista determina que el principal paquete de servicios públicos personificados se situe en la órbita centralista. Desde esta realidad se puede preguntar:

¿Es válido plantearse la existencia de Entes institucionales montados directamente en función de organizaciones municipales y no de organizaciones centrales?.

Si el conjunto de organizaciones institucionales, variadas y heterogéneas, quedan enmarcadas en la esfera de la Administración central, se produce en la práctica un desplazamiento de las propias actividades de esos Entes institucionales, hacia los centros de gestión y de poder más estrictamente centralistas. O lo que es lo mismo, si carecen las Administraciones municipales de "sus organizaciones institucionales", las materias propias de la gestión por éstas de parcelas de la vida local, se escapan de hecho de los centros gestores municipales, y ponen en grave peligro, tanto la dinámica de esa Organización institucional "centralizada", como la misma aptitud y calidad del servicio de interés comunitario que tal organización institucional tiene encomendado. El daño en definitiva radica en que como consecuencia de lo expuesto aparezca una parcela de la vida social, necesitada de atención pública, y que prácticamente quede, por el defecto organizativo apuntado, mal atendida.

Hoy se puede observar una notable pobreza de nuestra Administración municipal, en organizaciones institucionales que afronten con eficacia, problemas sectoriales surgidos en las áreas de las comunidades municipales. Existe una grave "fuga de organizaciones institucionales", desde los marcos municipales al marco central. Frecuentemente el Poder municipal que detecta una necesidad especifica, debe iniciar un penoso peregrinaje hacia organizaciones centralistas "para ofrecerles el tema", en solicitud de que se interesen por el mismo; consciente, de que aun con el peligro de que con el tratamiento centralista puedan perderse ricos matices, es éste el camino más realista para desarrollar ese problema, para encauzar esa inquietud, para, en definitiva.dar una respuesta a una exigencia de la vida social. $Y$ ante esta triste realidad, parece prudente afirmar que sería más interesante asentar en los propios centros del Poder municipal, la solución organizativa para esos problemas, para esas inquietudes municipales.

No se intenta defender la postura de que todas las actividades públicas que se realizan dentro de cualquier territorio municipal, deban ser asumidas por organizaciones funcionales del respectivo Ayuntamiento, pues debe ser una opción del Poder soberano del Estado, definir en cada coyuntura las reglas de coexistencia entre el ordenamiento jurídico estatal, los regionales y los locales, y dentro de éstos los municipales; de manera que cuando ello sea o parezca más conveniente para los intereses públicos deberá atribuirse la gestión de éstos a ámbitos del Poder central, y en otro 
caso a ámbitos de poder descentralizados-regional, provincial o municipal-.

Lo que sí se intenta subrayar es que la elección entre un Ente institucional de la Adminstración central y un Ente institucional de la Administración municipal en cuyo territoro se ha de prestar el servicio concreto, "suela resolverse con más frecuencia de la que seria deseable" a favor de la gestión del servicio por el Ente central, sin que esta decantación hacia esfera de poder centralista, encuentre en muchas ocasiones un sólido fundamento.

\section{3.-ORDENAMIENTO Y ORGANIZACION INSTITUCIONAL MUNICIPAL}

1.-Retomamos la doctrina del ordinamentalismo, a fin de valorar su posible encaje en la realidad del actual trataiento en España, de los Entes institucionales municipales. Se trata de examinar si el conjunto de la Administración institucional que existe en el Derecho municipal español, responde a los postulados que defiende la doctrina ordinamentalista para todo tipo de organizaciones públicas.

¿Son concebidos y regulados los Organismos institucionales de nuestros Ayuntamientos como ordenamientos sociales a los que da reconocimiento formal el Derecho político? ¿Pueden configurarse con libertad tales organizaciones? ¿Reconoce el Derecho positivo español ese ordenamiento informal en el yo social municipal? ¿Pueden los Ayuntamientos promover unos Estatutos, esto es, dar forma al ordenamiento social espontáneo, a la organización que se genera desde una necesidad concreta surgida en la comunidad municipal?.

2.-Descentralización y autonomía.

Para intentar una contestación a estas incógnitas, habrá que profundizar en los muy distintos significados de los términos descentralización y autonomía; o lo que es lo mismo, habremos de incorporar la idea de autonomía a la dialéctica de este trabajo.

Puede entenderse la centralización versus descentralización, como la situación resultante del ejercicio por el Poder de un conjunto de técnicas, por las que tras reconocer o conceder personalidad a distintos Entes integrados en el Estado, se dotan, definen y limitan las competencias atribuidas a cada uno de ellos. Que es cosa bien distinta de lo que puede entenderse por autonomia.

En un plano de filosofía política, autonomía viene a ser la vocación a un libre ejercicio de sus funciones peculiares que parte de esos Organismos tienen en mayor o menor medida. En un sentido de mayor rigor jurídico, la autonomía es la capacidad que esos mismos Entes tienen para 
dictarse las normas jurídicas que deben encauzar y orientar sus propias actividades.

En conclusión, será posible descentralizar sin autonomía, y también lo será comenzar con la descentralización un proceso hacia la autonomia. Autonomía y descentralización vienen a ser ideas situadas en planos conceptuales diferentes, que pueden complementarse, y pueden también constituirse en puntos de peligrosa confusión.

3.-Los rasgos diferenciadores de la autonomía, entendida como la vocación y la capacidad de un colectivo para autoregular sus singularidades diferenciadas, pueden ser los siguientes:

- supone la aceptación de una Soberanía a la que por definición se subordina. La autonomía no tiende a la disgregación sino al enriquecimiento del propio colectivo.

-si bien la autonomía se vivifica en la base del colectivo, se sanciona por el Poder soberano.

- la autonomía se define y defiende por poderes de dimensión política (la descentralización se corresponde a estructuras y valores más estrictamente administrativos).

4.- La doctrina ordinamentalista, enlaza pues la idea de autonomía con la de ordenamiento social espontáneo, y adjudica aquella cualidad a éste.

5.-Estos ordenamientos espontáneos sólo pueden detectarse en medios sociales naturales. Entre los que se encuentran los Ayuntamientos.

6.-Y lo que habrá entonces que afirmar, es el derecho autonómico de los Ayuntamientos, a la creación libre de las organizaciones institucionales que resulten acordes con sus necesidades propias.

7.-Y lo que por otra parte habrá que cuestionar, es si la autonomía municipal preconizada por el art. 140 de la Constitución, y definida entre otras, en la sentencia del Tribunal constitucional de 2 de Febrero de 1.981, ha impregnado debidamente a los Organismos institucionales de los Ayuntamientos.

\section{4.-ANALISIS ORDINAMENTALISTA SOBRE LOS ENTES INSTITUCIONALES DE LOS AYUNTAMIENTOS}

\section{1.-La creación del Ente institucional municipal}

\subsection{1.-La municipalización.}

El Real Decreto $1.710 / 79$ de 16 de Junio ha liberado de trámites autorizantes centralistas a un buen paquete de expedientes municipalizadores. 
Con ello, el clásico significado de "formidable sistema de obstáculos»(8), con el que se calificaba el procedimiento municipalizador de un servicio público, está dando paso-quizás con excesiva lentitud-, a una concepción más racional que entiende la municipalización como un proceso de estudio y de réflexión a través del cual un Ayuntamiento comprende que debe gestionar cierta parcela de la actividad social, y analiza las condiciones económicas, jurídicas, técnicas y sociales que influirán para la feliz puesta en marcha de la empresa.

\subsection{2.-Las ideas de empresa y de convenio.}

El expediente municipalizador debe poner especial énfasis en el talante de empresa, que lleva de suyo a resolver con eficacia la ecuación producto-productividad, y a mantener una permanente tensión sobre el equilibrio inestable de la carga y el beneficio.

En los Entes institucionales de carácter asociativo, también tendrá un sentido direccional, la idea de concierto de voluntades: A ella se ha referido con reiteración el Tribunal Supremo, entre otras en las sentencias de 8 de Noviembre de 1.961, 1 de Noviembre de 1.966 y 18 de Diciembre de 1.967 .

\subsection{3.-El poder organizativo.}

Desde los anteriores presupuestos, será el poder organizatorio más o menos autonómico del propio Ayuntamiento, el que dé vida al nuevo Organismo institucional, y el que moldee sus competencias y su funcionalidad para la prestación de un servicio público de interés municipal.

Y en este particular quizás se haya avanzado poco: Subsisten en efecto importantes y quizás excesivos controles centralistas.

\section{2.-El ordenamiento del Ente institucional municipal}

\subsection{1. - La organización externa del Ente.}

El Reglamento municipal independiente, esto es, el que puede elaborarse desde la autonomia municipal al margen aunque sin oposicion al Reglamento estatal, sigue sin recibir un definitivo respaldo, salvo alguna limitada línea jurisprudencial-ss.T.S. de 15 de Marzo y de 19 de Mayo de $1.971-$, y doctrinal-con la denominada teorla de la norma habilitante(9)-.

La homologación centralista del Reglamento municipal, es en todo caso más patente en los Estatutos de los Organismos asociativos que en los creadores de Organismos gestores:

Aquellos en efecto están sometidos a controles importantes-arts. 13.1, 16.2 y 107 del Real Decreto 3046/77 de 6 de Octubre-. Mientras que 
éstos siguen sometidos al procedimiento de los arts. 109 y 110 de la Ley de régimen local-vide el art. 86 del Reglamento de Servicios-. Salvo los supuestos de Madrid y Barcelona contemplados en los apartados 7.6 y 7.7 del art. 1 del Real Decreto 1.710/79 de 16 de Junio.

Parece que si el Ayuntamiento debe disponer de la potestad organizatoria, conviene que también tenga la potestad decisoria sobre la aprobación de los Estatutos de sus Entes institucionales, y que se reduzca la conexión con el Poder central a las técnicas al uso en otros paises europeos de nuestro entorno cultural, del corte del Dictamen consultivo, o del Dictamen vinculante sólo a efectos de subvenciones; o de la obvia potestad de denuncia ante el Poder judicial.

\subsection{2. - La organización interna del Ente.}

En un trabajo anterior(10) se intenta resaltar la peligrosa falta de atención del legislador respecto al entramado orgánico de estos Organismos. En parte debido a la falta de una regulación legal por mínima que ésta fuera, sobre los elementos y los instrumentos jurídicos de que debe disponer cualquiera de estos Entes, se han alumbrado Organismos endémicos, sin capacidad para desarrollar una actividad seria en la vida social.

Alguna huérfana sentencia del Tribunal Supremo, como la de 12 de Mayo de 1.978 sí analiza las prerrogativas, los órganos y los fines de estos Entes, compendiándolos y comprendiéndolos como categoría jurídica unitaria necesitada de clarificación normativa; y son por ello una inestimable aportación doctrinal.

Es necesaria la clarificación de los órganos, tanto de los decisorios como de los de trabajo; incluso definiendo los parámetros clarificadores de los status de su personal-tema en el que han sido adelantadas, las ss.T.S. de 12 de Diciembre de 1.964 y 13 de Junio de 1.967-. Clarificación de su patrimonio-art. 9del Reglamento de bienes de las Corporaciones locales, y art. 86 del Reglamento de servicios de las Entidades locales-, de sus Presupuestos-art. 72 del Reglamento de servicios y tratamiento en la Ley 40/81 de 28 de Octubre-, y de su Poder fiscal-art. 129 del Real Decreto $3.250 / 76$ de 30 de Diciembre. Clarificación de sus medios jurídicos-potestades exorbitantes, con especial referencia a la expropiatoria contemplada en el art. 85 de la Ley de expropiación forzosa, y, entre otros, en el art. 187 del Reglamento de gestión urbanística; así como de la potestad sancionadora y del régimen de recursos que pueden incorporarse contra sus actos administrativos-. Y por último, clarificación del casi inexistente soporte formal del Ente.

El balance no parece que ofrezca un saldo favorable, ni en contraste teórico con los postulados de la doctrina ordinamentalista, ni en contraste con la realidad. 
Ni la Ley estatal ha abierto cauces, ni el Poder central ha permitido en el pasado que los Ayuntamientos los abrieran.

El resultado puede parecerse al que se esquematiza a continuación:

4.3.-Análisis tipológico de los Organismos institucionales de los Ayuntamientos.

\subsection{1.-De la Mancomunidad.}

Es un órgano consensual, formado por la asociación de Ayuntamientos, para la prestación de específicos servicios municipales.

Se caracteriza por ser una asociación voluntaria, de carácter netamente administrativo, formada por Entes locales aunque sean de diversas esferas(11). ,

Parece obligada la referencia al Dictamen del Consejo de Estado de 7 de Enero de 1.966:

"Indiscutible por esencia la posibilidad de que entren a formar parte de las Mancomunidades los Municipios, parece preciso asimismo, que puedan formar parte de ellas las Entidades locales menores, por la obvia razón de que éstas aparecen subrogadas en parcelas de la competencia municipal que pueden constituir fines de Mancomunidades... Parece asimismo que puedan formar parte de ellas las Diputaciones, tanto por no existir precepto legal o reglamentario que lo impida, como por razones positivas de que la esfera de competencia de las Mancomunidades puede suponer coincidencia con la de las Diputaciones".

Su ordenamiento se rige por lo dispuesto en el art. 15 del Real Decreto 3.046/77 de 6 de Octubre.

Los Estatutos analizados presentan gran variedad respecto a la composición-abierta o cerrada en cuanto a miembros y en cuanto a servicios-, un repetitivo tratamiento orgánico con una Gestora y un Presidente, decantado irremediablemente a favor del Ayuntamiento con mayor peso específico en la Mancomunidad, y la aplicación de dos valores-el presupuestario o el de la población del respectivo Municipio-a la hora de definir los criterios de reparto de las cargas de la Mancomunidad.

No se tiene conocimiento de haberse llevado a la práctica esa original Mancomunidad urbanística, un tanto extravagante al residenciarse en ella ciertas competencias urbanísticas, que puede "delegar" en los Ayuntamientos miembros: la penosa redacción del art. 216 de la Ley del Suelo se ha dulcificado en los arts. 10 y 11 del Reglamento de gestión urbaniśtica.

Una simple referencia puntual, por último, a algunas figuras atípicas, 
como la Mancomunidad de los Canales del Taibilla-la "V" originaria ha crecido por mor de algún duendecillo-, y como el Asocio de la extinguida Universidad y tierra de Avila.

\subsection{2.-Del Consorcio.}

Es un Organismo consensual, formado por la asociación de Entes locales y otros Entes públicos, para la prestación de específicos servicios públicos.

Se caracteriza por ser una asociación voluntaria, de carácter privado o - administrativo-en este particular radica buena parte de la importante tensión doctrinal que suscita el estudio de esta figura\{12). La voluntad de los Entes locales encuentra en el Consorcio una natural limitación en la voluntad estatal, lo que justifica la intervención de la Administración central en la aprobación de la norma estatutaria constitutiva del Consorcio.

Salvo alguna ligera referencia en el art. 170.20 del Reglamento de Organización, funcionamiento y régimen jurídico de las Corporaciones locales, el Consorcio se encontraba prácticamente relegado en la legislación local de 1.955-ya que el desencajado art. 37 del Reglamento de servicios de las Entidades locales, no tuvo mayor proyección-. El art. 107 del Real Decreto 3.046/77 de 6 de Octubre les otorga en todo caso la consideraciónde Entes locales.

El análisis de diferentes textos estatutarios, presenta respecto a la composición de los Consorcios, la original variable de que se desliza como de rondón, algún que otro órgano centralista generalmente carente de personalidad(13), e incluso a personal técnico. Sus órganos de gobierno ofrecen como resultado, una heterogeneidad variopinta que culmina en la frecuente asignación de la Presidencia al Gobernador civil de la Provincia. En el régimen de sesiones se detecta incluso algún poder de veto a favor de representantes centralistas(14).

Tiene cierta originalidad y ambivalencia, el hipotético Consorcio urbanístico contemplado en los arts 12 y siguientes del Reglamento de gestión urbanistica.

\subsection{3.-De la Agrupación.}

Es una forma residual, en la que se pueden comprender figuras orgánicas muy diferentes:

- Agrupación forzosa estricta, contemplada en el art. 2.1. del Real Decreto 3.046/77 de 6 de Octubre.

-Agrupación para la ejecución de obras subvencionadas por el Estado. Art. 16.1 del mismo Real Decreto. Y quizá la extraña figura del art. 9.2. del Reglamento de gestión urbanística. 
-Agrupación histórica. Art. 17.1 del repetido Real Decreto.

¿Hay un ordenamiento jurídico en estas Agrupaciones? Quizás la contestación deba ser negativa, desde la imposición estatal que suele caracterizar a estas figuras: Así, el art. 38 de la Ley de 24 de Junio de 1.955, y el art. 15 de la Ley $48 / 66$ de 23 de Julio, tanto respecto a la Agrupación impuesta $-n .^{\circ} 3-$, como respecto a la misma Agrupación voluntaria-n. ${ }^{\circ}$ $1-$. Y a pesar del ensanchamiento que el contenido de estas Organizaciones tiene en el Real Decreto 3.046/77 de 6 de Octubre, y muy en particular su art. 8 (en relación con el art. 217 de la Ley del Suelo), no parece que pueda darse hoy dia una contestación positiva. Con lo que se debe concluir en una valoración global, absolutamente negativa.

\subsection{4.-De la Fundación pública del servicio.}

Es una persona jurídico pública, cuyo origen es de tipo fundacional(15), en la que novedosos contenidos económicos han difuminado sus remotos caracteres asistenciales y culturales que la definian.

En efecto, sus tradicionales fines asistenciales, van a dar paso a finalidades más acordes con el moderno intervencionismo económico. p.ej. los Patronatos de la vivienda.

En la medida en que se juzgue necesario el intervencionismo económico, se vigorizará esta fórmula de gestión de servicios, que hasta hace pocos años, atenazada por la necesidad de previo expediente municipalizador de control centralista, ha sufrido una larga y aletargada supervivencia.

En el art. 86.2 del Reglamento de Servicios de las Corporaciones locales, se centra la regulación normativa de estos Entes institucionales.

En los aletargados Estatutos que se han analizado, predominan los contenidos de carácter cultural sobre los económicos, y se observa una importante presencia y aun control próximo de los poderes de los Ayuntamientos sobre la Fundación. Quizás aquí haya que culpar a los propios Ayuntamientos de falta de voluntad autonómica.

\subsection{5.-De la Sociedad municipal.}

Es una persona jurídico-privada, que tiene un contenido fundamentalmente patrimonial, que ofrece algunos contornos imprecisos(16), con algunas de sus parcelas sujetas al Derecho administrativo.

Se debe enfatizar también aquí, en la medida en que a ello no haya alcanzado el Real Decreto 1.710/79-liberalizador-sobre los graves condicionamientos de la Empresa municipal sujeta a expediente municipalizador.

Los arts. 60.4 y 92 del Reglamento de Servicios de las Corporaciones 
locales, nuclean el ordenamiento de estos Organismos.

La patrimonialización de las acciones en mano municipal, no ha sido en todo caso suficientemente explotado, ya que son muy pocas las experiencias municipales que se han realizado.

\title{
4.3.6.-De la Empresa mixta.
}

Es una persona juridica privada, con contenido igualmente patrimonial. Se diferencia de la Sociedad municipal en que su dimensión privatista es más acusada, ante la presencia de intereses patrimoniales diferentes del municipal, y ante la imposibilidad de formalizar actuaciones con moldes administrativos precisamente por la presencia de tales intereses privados en la Sociedad.

Esta figura organizativa arrastra también toda la carga del previo expediente municipalización, lo que salvo alguna excepción-promociones de Iresco-Mercasa - , la ha dejado reducido a supuestos de liquidación de concesiones de servicios públicos o publificados; a base de asumir directamente su gestión el Ayuntamiento, y de aplazar el rescate patrimonial durante un periodo transaccional abocado en todo caso a una definitiva formula de Empresa municipal. Se trata pues de una fórmula-puente, a la que es de especial aplicación las pautas fijadas en los arts. 104 y 143 y siguientes del Reglamento de Servicios de las Corporaciones locales.

\author{
NOTAS:
}

(1) En «El ordenamiento jurídicon, Ed. Instituto de estudios políticos. Madrid, 1.963. pp. 213 y 132. Vide también ROUSSEAU en "El contrato social", Ed. Edaf, Madrid, 1.969, pp. 24 y 37 . Y HAURIOUS en "Principios de Derecho público y constitucional", concretamente el Apéndice sobre "La libertad política y la personalidad moral del Estadon, Ed. Reus. Madrid, 1. 927, p. 529.

(2) En su Prólogo, a «El ordenamiento jurídico» precitado, p. 15.

(3) En su Prólogo a "Teoría general del Estado", de G. JELLINEK, Ed. Albatros. Buenos Aires, 1.973, p. XIX.

(4) Y que fuerza a razonamientos aplicativos de especial dificultad, como los contenidos en el Dictamen del Consejo de Estado de 15 de Enero de 1.970 en torno a la naturaleza de los sindicatos existentes en la fecha.

(5) ARIÑO en "Descentralización y planificación", Ed. I.E.A.L., Madrid, 1.972, p. 14.

(6) La s. T. Supremo de 29 de Octubre de 1.967 Ilega a decir: «...la competencia urbanística de los Municipios ha sido absorbida prácticamente por los órganos centrales o periféricos de la Administración central». 
(7) El primero en La Administración local y los problemas de la renovación urbanan, Ed. Servicio de publicaciones del Ministerio de la Vivienda. Madrid, 1.961, p. 22. Y el segundo en "Lecciones de Derecho urbanístico", T. I, Ed. Civitas, Madrid, 1.979, p. 100.

(8) GARCIA DE ENTERRIA en "La actividad mercantil e industrial de los Municipios", R.A.P. n. ${ }^{\circ} 17 / 55$, p. 111.

(9) BAENA en "Administración central y Administración institucional en el Derecho españoln, Ed. Instituto estudios administrativos. Madrid, 1.976, p. 208. Mi trabajo, "Los Reglamentos municipales en la reciente Jurisprudencia del Tribunal supremon, R. A. P. n. ${ }^{\circ}$ 78/1.975.

(10) En «Presupuestos e instrumentos para la funcionalidad de los Organismos institucionales de los Ayuntamientos", pendiente de publicación en la Revista estudios vida local.

(11) ALVAREZ GENDIN en "Perspectivas actuales de la descentralización", Ed. Escuela nacional de Administración pública, Madrid, 1.971, la monografia "Problemas sobre la descentralización administrativa a nivel provincial o regional", p. 53. El mismo, en "Las mancomunidades municipales", Ed. Revista de Archivos, Bibliotecas y Museos, Madrid, 1.921, p. 2. ALBI en "Tratado de los modos de gestión de las Corporaciones locales", Ed. Aguilar, Madrid, 1.960, p. 419. Y GARRIDO FALLA en "Administración indirecta del Estado y descentralización funcional, Ed. I.E.A.L., Madrid, 1.950, p. 20, y en "La descentralización administrativa", Ed. Universidad de Costa Rica, 1.967, p. 27.

En apoyo de la referencia puntual del texto, a la Mancomunidad de los canales del Taibilla, valga una referencia al Dictamen del Consejo de Estado de 7 de Enero de 1.966. Y respecto al Asocio de Avila, las ss. T. S. de 10 y 11 de Junio de 1.974.

(12) MARTIN MATEO en "Los consorcios locales", Ed. I.E.A.L., Madrid, 1.970, y STANCANELLI en "Los consorcios en el Derecho Administrativo", Ed. Enap, Madrid, 1.972.

(13) Así, el art. 14 de los Estatutos del Consorcio del Gran Bilbao, contemplaba-con voz y sin voto-a la Diputación y a la Dirección General de Obras hidráulicas, que no se encuentran en la enumeración de miembros contenida en su art. 1.

(14) Art. 9 de los Estatutos del Consorcio de la Marina baja de Alicante.

(15) BAENA en "Administración central y Administración institucional en el Derecho español", Ed. Instituto estudios administrativos, Madrid, 1.976, p. 176. Y CLAVERO en "Personalidad juridica, derecho general y derecho singular en las Administraciones autónomas" en la Revista "Documentación administrativa", $n$. $^{\circ} 58$. Una referencia a los arts. 6 y 28 de los Estatutos del Instituto de investigación de la Comarca La Safor, de Valencia.

(16) BAENA en Régimen juridico de la intervención administrativa en al Economian, Ed. Tecnos, Madrid, 1.966, p. 237. BROSETA en «Las Empresas públicas en forma de Sociedad Anoniman, p. 287.

Tienen singular interés los Estatutos de la Sociedad Anónima Roche del Ayuntamiento de Conil de la Frontera en Cádiz.

Una cita a la sentencia del T. S. de 16 de Marzo de 1.973, y al Dictamen del Consejo de Estado de 19 de Junio de 1.969. 